\title{
Applying Causal Reasoning to Analyze Value Systems
}

\author{
Patrícia Macedo $^{1,2}$ and Luis M. Camarinha-Matos ${ }^{1}$ \\ ${ }^{1}$ Faculty of Sciences and Technology, Universidade Nova de Lisboa, Portugal \\ pmacedo@est.ips.pt \\ ${ }^{2}$ Polytechnic Institute of Setubal, Portugal \\ cam@uninova.pt
}

\begin{abstract}
Collaborative networked organizations are composed of heterogeneous and autonomous entities. Thus it is natural that each member has its own set of values and preferences, as a result, conflicts among partners might emerge due to some values misalignment. Therefore, tools to support the analysis of Value Systems in a collaborative context are relevant to improve the network management. Since a Value System reflects the set of values and preferences of an actor, which are cognitive issues, a cognitive approach based on qualitative causal maps is suggested. Qualitative inference methods are presented in order to assess the potential for conflicts among network members and the positive impact between members' Value Systems. The software tool developed, in order to support the proposed framework and the qualitative inference methods, is briefly presented.
\end{abstract}

Keywords: Collaborative networks, value systems, causal reasoning.

\section{Introduction}

Collaborative networked organizations (CNO) are formed by heterogeneous and autonomous entities. Thus, it is natural that each member has its own set of values and preferences; as a result, they will have different perceptions of outcomes, which might lead to non-collaborative behaviour. In recent years some studies have explored the importance of Value Systems in the context of networked organizations [1-4]. Furthermore, some efforts have been done to develop methods to analyze Value Systems in collaborative environments [5, 6]. These preliminary efforts have revealed that a cognitive approach based on causal maps was a promising way; however, a consistent qualitative approach has not yet been explored. Behavioural researchers [7, 8] have concluded that a qualitative approach has the advantage of being close to natural language; thus, decisions makers and experts can understand the model easily, which will increase the confidence on the outputs. Departing from the work developed on cognitive maps by Eden [9], and the work done on qualitative operators for reasoning maps by Montibeller and Belton [10], a qualitative inference approach has been developed in order to assess the potential for conflicts among network members and the positive impact between members' Value Systems. 


\section{Contribution to Technological Innovation}

Collaborative networks constitute an important organizational structure to promote innovation, namely in the context of small and medium size enterprises. This research aims to contribute to technological innovation in the way that it will provide new methods and tools to support CNO management in the scope of Value Systems management and analysis. The presented qualitative approach is a step forward in the area of the analysis of Value Systems alignment, since it proposes applying qualitative causal reasoning to infer qualitative indicators about Value Systems alignment in a collaborative context. Another contribution to technological innovation is the development of a prototype that implements the analysis framework and the qualitative reasoning methods in an integrated and distributive mode, which may boost the development of new consulting services in the management of collaborative networks.

\section{Related Work on Values Alignment}

Values alignment in an organizational context is a topic that has been studied essentially by social sciences researchers. Brian Hall [11] and Richard Barrett [12] developed models of values in organizations and analyzed the importance of values management for the success of organizations. Richard Barrett also studied the alignment between employees' core-values and enterprise's core-values. On the other hand, Eden [9] used causal maps to represent the cognitive structure of core-values, also establishing the relationships between organizational goals and core-values. Another cognitive approach was proposed by Rekom and his colleagues [13] as a method to identify the core-values held by organizations based on their employees daily actions.

\section{Core Value System Analysis Extended-Framework}

The base concepts on Value Systems and Core Value System analysis are briefly described, in order to facilitate the understanding of the proposed approach.

Core Value System: base concepts. The adopted Core Value System (CVS) conceptual model assumes that core-values are the core characteristics of the organization (or network of organizations) to be evaluated. The Value System is decomposed in two subsystems. The first subsystem - core value objects subsystem (COS) - is represented by the organization (or networked organization) itself. The second one - core evaluation subsystem (CES) - represents the mechanisms of evaluation, such as the functions to evaluate the organization's core-values, the core-evaluation perspective and the core-values themselves.

The set of core-values and respective preferences of an actor are represented according to this conceptual model by the core-evaluation perspective. The coreevaluation perspective will be the main structural element in the proposed approach. A detailed and formal description of these concepts can be found in $[6,14]$.

Core Value System analysis extended-framework. In order to analyze core-values in a collaborative network, a model that supports the analysis of the relationships among: core-values, organizations, and collaborative networks, is required. This kind 
of relationships can be modelled using graphs. The idea is to represent a network in symbolic terms, abstracting reality as a set of linked nodes. In this case, each node represents an element (a network, an organization, or a core-value) and the directed arcs specify the relationships. The causal modelling method is used to model the causal relationships among core-values in order to analyze the influence among them. Considering the nature of this analysis, a combination of these two modelling techniques was suggested in the framework proposed by Camarinha-Matos et al. [5]. However, the mentioned framework does not support the actor's preferences. As preferences are one of the main elements of a Core Value System it is fundamental to consider them in the Core Value System analysis process. Although the preferences were first modelled in a crisp mode (see [14]), in this approach it is proposed to represent them in a qualitative way.

Although, the previous framework considered that all influences among corevalues had a similar strength, it may be also important to be able to model different intensities of influence. Thus, it is proposed to extend the CVS analysis framework in order to add the following properties to the maps (see Fig. 1): (i) in core-values influence map the width of the direct-edge represents the strength of the influence; (ii) in organisations' core-values map and CNO's core-values maps the edges of the graphs have different widths according to the degree of importance of the core-value.

\begin{tabular}{|c|c|c|}
\hline Core-Values & Organization & CNO \\
\hline Core-values influence map & Organizations' & CNO's core-values \\
\hline $\begin{array}{l}\text { core-values influence positively } \\
\text { or negatively each other, and the } \\
\text { intensity of the influence. } \\
\text { Type of relantionship }\end{array}$ & $\begin{array}{l}\text { Use graphs to show the } \\
\text { core-values held by each } \\
\text { organization, and the core- } \\
\text { values shared by organiza- } \\
\text { tions. }\end{array}$ & $\begin{array}{l}\text { map } \\
\text { Use graphs to show the } \\
\text { core-values held by the } \\
\text { CNO, and the core-values } \\
\text { shared by CNOs. }\end{array}$ \\
\hline $\begin{array}{l}\text { Positive influence relationship } \\
\qquad \mathrm{cv1} \longrightarrow \mathrm{cv} 2\end{array}$ & $\begin{array}{l}\text { Organization } 01 \text { holds } \\
\text { the core-value cvl. }\end{array}$ & $\begin{array}{l}\text { CNO1 holds the core- } \\
\text { value cvl. }\end{array}$ \\
\hline $\begin{array}{l}\text { Negative influence relationship } \\
\text { Intensity of the relationship: }\end{array}$ & & CNO 1 \\
\hline $\begin{aligned} \text { strong } & \longrightarrow \\
\text { moderate } & \longrightarrow \\
\text { weak } & \longrightarrow\end{aligned}$ & $\begin{array}{r}\text { Degree of importance: } \\
\text { high } \\
\text { fair } \\
\text { low } \\
-\ldots-1 . . .\end{array}$ & 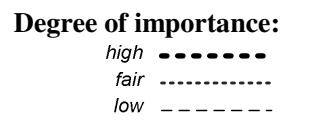 \\
\hline
\end{tabular}

Fig. 1. Core Value System analysis extended-framework

Formally, the three types of maps proposed in the extended-framework are formally specified as direct graphs.

Definition 1 (Organization's core-value map) - The organization's core-value map is defined as an ordered pair, OCVM $=(V, O W)$

- $\mathrm{V}=\mathrm{CV} \cup \mathrm{O}, \mathrm{CV}$ is the set of core values, $\mathrm{O}$ is the set of organizations

- OW is a set of relations (edges).

$O W=\left\{o w_{i j}=\left(o_{i}, c v_{j}, p\right): o_{i} \in O \wedge c v_{j} \in C V \wedge p \in D I=\{l o w\right.$, fair, high $\left.\}\right\}$. The preference operator is defined as: preference: $O W \rightarrow D I$, preference $(o, c v, p)=p$. 
Definition 2 (CNO's core-value map) - The CNO's core-value map is defined as an ordered pair, $C C V M=(V, C W)$.

- $\mathrm{V}=\mathrm{CV} \cup \mathrm{CNO}, \mathrm{CV}$ is the set of core values, $\mathrm{CNO}$ is the set of networked organizations.

- $\mathrm{CW}$ is a set of relations (edges).

$\mathrm{CW}=\left\{c w_{i j}=\left(c n o_{i}, c v_{j}, p\right): \mathrm{Cno}_{\mathrm{i}} \in \mathrm{CNO} \wedge \mathrm{cv}_{\mathrm{j}} \in \mathrm{CV} \wedge \mathrm{p} \in \mathrm{DI}=\{\right.$ low, fair, high $\left.\}\right\}$. The preference operator is defined:

preference: $C W \rightarrow D I$, preference $($ cno, $c v, p)=p$.

Definition 3 (Core-values influence map) - A core-values influence map is defined by an ordered pair : $C V I M=(C V, E)$ where,

- $\quad \mathrm{CV}$ is the set of core values.

- $\quad E$ is the set of influences (edges)

$$
\begin{aligned}
E=\left\{e_{i j}=\left(c v_{i}, c v_{j}, p, s\right): c v_{i} \in C V \wedge c v_{j} \in C V \wedge p \in P\right. \\
=\{\text { weak, moderate, strong }\} \wedge s \in S=\{+1,0,-1\}\} .
\end{aligned}
$$

- The following operators are defined:

influenceValue: $E \rightarrow P \times S$, influenceValue $\left(c v_{i}, c v_{j}, p, s\right)=(p, s)$, signal: $E \rightarrow S$, $\operatorname{signal}\left(c v_{i}, c v_{j}, p, s\right)=s$, intensity: $E \rightarrow P$, intensity $\left(c v_{i}, c v_{j}, p, s\right)=p$.

The example maps presented in Fig. 2 illustrate how to use the extended framework to represent the core-values held by a $\mathrm{CNO}$ and its members. Each map corresponds to one of the three types of maps proposed:

1. Core-values influence map -illustrates the influence relationships among the seven core-values IInovation, Knowledge, Profit, Quality, Standardization, Social Awareness, Uniqueness $\}$.

2. Organization's core-values map - illustrates the core-values held by the organizations Research Center, University A, and Factory A, as well as the corresponding degree of importance of each core-value.

3. CNO's core-values map - illustrates the core-values held by the virtual organization VO1, and the corresponding degree of importance of each core-value.

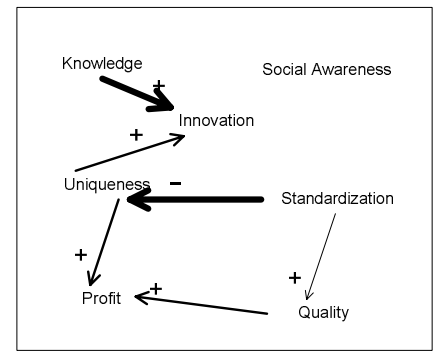

Core-values influence map

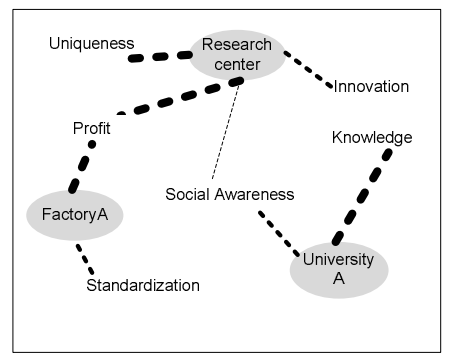

Organization's core-values map

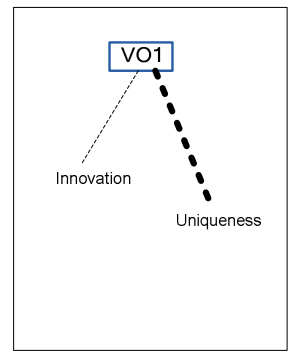

CNO's core-values map

Fig. 2. Extended-framework maps- example 


\section{Core Value System Analysis Methods}

Observing the example represented in the causal map of Fig. 2, we can notice that Standardization influences Quality positively in a direct way. Nevertheless, as on one hand Standardization influences Quality, and Quality influences Profit, and on the other hand Standardization influences Uniqueness, and Uniqueness influences Profit, we can also deduce that Standardization influences Profit in an indirect way.

Thus, we can define two kinds of influence relationships: the direct influence and the indirect influence.

Definition 4 (Direct influence) - A core-value $c v_{i}$ is said to have a direct influence on a core-value $c v_{j}$ if there is a direct link from the node $c v_{i}$ to the node $c v_{j}$.

Definition 5 (Indirect influence) - A core value $c v_{i}$ is said to influence indirectly $c v_{j}$, if there is a node $c v_{k}$, such that $c v_{i}$ has a direct influence in $c v_{k}$ and $c v_{k}$ has an influence (direct or indirect) on $c v_{j}$.

In order to infer the composite influence relationship between two core-values, the following operations have to be performed (see Fig. 3):

1. Determine all indirect influences.

2. Determine the result from joining all indirect influences, calculated in (1).

3. Determine the result of the composition of the direct influences with the joint influences, calculated in (2).

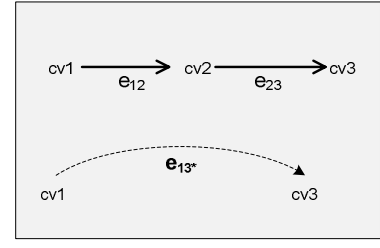

(1) Indirect inferred influence

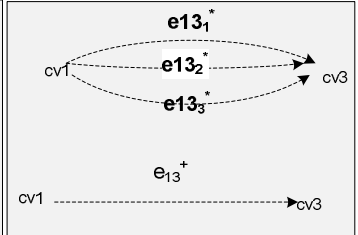

(2) Joint indirect influence

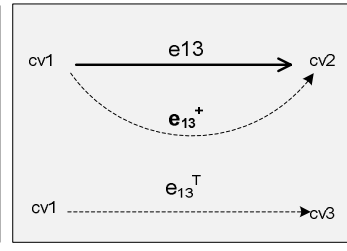

(3) Composite influence

Fig. 3. Inference Operations

In order to characterize each inferred influence relationship, it is necessary to specify how its intensity and signal can be determined. In order to determine the resulted intensity of the indirect influence a recursive approach is used and it is assumed that there is a decision table decT1 (see Table 1 as an example) with the following specification, $\operatorname{decT1} P^{2} \rightarrow P$ (for $P$ specification see Definition 3).

Table 1. Decision Table (decT1) example

\begin{tabular}{|l|l|l|l|}
\hline \multicolumn{1}{|c|}{ decT1(p1,p2) } & weak & \multicolumn{1}{c|}{ moderate } & \multicolumn{1}{c|}{ strong } \\
\hline weak & weak & weak & weak \\
\hline moderate & weak & moderate & moderate \\
\hline strong & weak & moderate & strong \\
\hline
\end{tabular}


Thus, the indirect influence value is recursively defined as:

indirectIValue: $E^{*} \rightarrow P \times S$
indirectIValue $\left(e i j_{n}{ }^{*}\right)$
$=\left\{\begin{array}{cc}\text { influenceValue }(e i j) & \text { if } \text { cv }_{\boldsymbol{i}} \text { has a direct influence in } \boldsymbol{c v}_{\boldsymbol{j}} \\ \left(\operatorname{decT1} 1\left(\operatorname{intensity}(e i k), \text { intensity }\left(e k j_{n}{ }^{*}\right)\right), \operatorname{signal}(e i k) \times \operatorname{signal}\left(e j_{n}{ }^{*}\right)\right) & \text { otherwise }\end{array}\right.$

Definition 6 (Joint indirect influence) - Joint indirect influence of $c v_{i}$ on $c v_{j}$ is the result of the "junction" of one or more indirect influences of $c v_{i}$ on $c v_{j}$. The intensity and signal of the joint influences can be inferred as suggested below.

Let us assume that: $e i j_{n}{ }^{+}<=>$Joint indirect influence $\left(\left\{e i j_{1} * e i j_{2} *, \ldots e i j_{n}{ }^{*}\right\}\right)$ and a decision table decT2: $(\mathrm{P} \times \mathrm{S})^{2} \rightarrow \mathrm{P} \times \mathrm{S}$ (of the kind of decT1 defined above) was defined in order to determine the signal and intensity of the aggregation of two indirect influences.

So, the intensity and signal of the joint indirect influence is defined recursively.

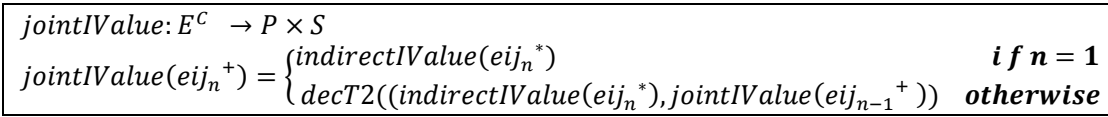

Definition 7 (Composite influence) - The composite influence is determined by the aggregation of two components: the direct influence and the joint indirect influence. The intensity and signal of the composite influence can be inferred as it is suggested below:

- $\quad e i j^{C}=$ Composite influence $\left(e i j, e i j^{+}\right)$.

- A decision table (of the kind of decT1 defined above) decT3: $(\mathrm{P} \times \mathrm{S})^{2} \rightarrow \mathrm{P} \times \mathrm{S}$ has to be defined in order to determine the signal and intensity of the aggregation of the direct influence and the joint indirect influence.

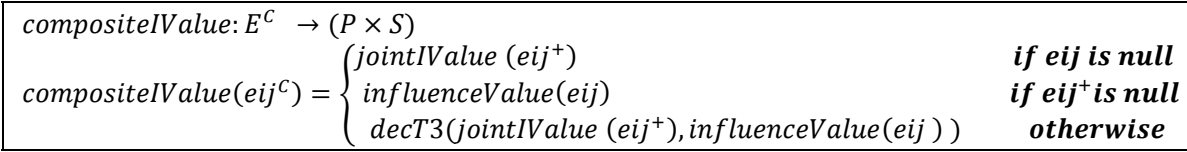

After the composite influence between two core-values has been calculated, it is possible to determine the two alignment metrics introduced in[5]: (i) the number of positive impacts between two Core Value Systems; (ii) the number of potential conflicts between two Core Value Systems.

Definition 8 (Positive impact) - There is a positive impact between two Core Value Systems , $C V S_{x}$ and $C V S_{y}$, if there is a core-value $c v_{i}$ that belongs to $C V S_{\mathrm{x}}$ and a corevalue $c v_{j}$ that belongs to $C V S_{y}$, such that $c v_{i}$ influences positively $c v_{j}$.

Let us consider $\mathrm{PI}_{\mathrm{xy}}$ as the set of positive impacts of $C V S_{x}$ in $C V S_{y}$ :

$$
P I_{x y}=\left\{e i j^{C}: \operatorname{signal}\left(e i j^{C}\right)=1 \wedge c v_{i} \in C V S_{x} \wedge c v_{j} \in C V S_{y}\right\}
$$

The impact intensity depends on two factors: (i) the intensity of the influence relationship; (ii) the degree of importance of the value (in the example of Fig. 2, Knowledge has a positive impact on Innovation, but as Innovation has a low degree of importance to VO1, the University's CVS has not a high positive impact on VO1's CVS). 
The combination of these two factors is defined through a decision table (see Table 2), decT4: $P \times D I \rightarrow D I$. ( for PI specification see definition 3 and for DI specification see definition 2). Thus, the impact intensity is defined as:

impactIntensity: $E^{C} \rightarrow D I=\{l o w$, fair, high $\}$.

impactIntensity $\left(e i j^{C}\right)=\operatorname{decT} 4\left(\operatorname{intensity}\left(e i j^{C}\right)\right.$, preference $\left.\left(o w_{y j}\right)\right)$.

Table 2. Decision Table (decT4) example

\begin{tabular}{|c|l|l|l|}
\hline decT4 (x,y) & \multicolumn{1}{|c|}{ low } & \multicolumn{1}{c|}{ fair } & \multicolumn{1}{c|}{ high } \\
\hline weak & low & low & fair \\
\hline moderate & low & fair & high \\
\hline strong & low & fair & high \\
\hline
\end{tabular}

Definition 9 (Potential for conflict) - It is considered that a conflict between $C V S_{x}$ and $C V S_{y}$ exists if there is a core-value $c v_{i}$ that belongs to $C V S_{x}$ and a core-value $c v_{j}$ that belongs to a $C V S_{y}$, such that $c v_{i}$ influences negatively $c v_{j}$, or $c v_{j}$ influences negatively $c v_{i}$.

Let's define $C I_{x y}$ as the set of conflicts between $C V S_{x}$ and $C V S_{y}$ :

$$
\begin{gathered}
C I_{x y}=\left\{e i j^{C}: \operatorname{signal}\left(e i j^{C}\right)=-1 \wedge\left(c v_{i} \in C V S_{x} \wedge c v_{j} \in C V S_{y}\right)\right\} \\
\cup\left\{e j i^{C}: \operatorname{signal}\left(e j i^{T}\right)=-1 \wedge\left(c v_{i} \in C V S_{x} \wedge c v_{j} \in C V S_{y}\right)\right\}
\end{gathered}
$$

Like the positive impact intensity, the intensity of the conflict also depends on the intensity of the influence and the degree of importance of the core value. Thus, a similar inference process is suggested to determine the conflict intensity.

Application example: The mentioned inference methods were implemented in SWIProlog. Fig. 4 shows the main rules to implement the positive impacts assessment and the potential for conflicts assessment.

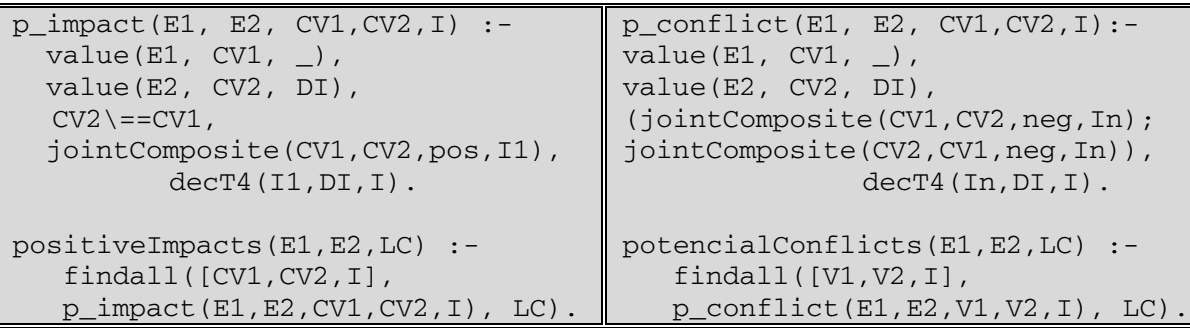

Fig. 4. Prolog implementation

Let us take Fig. 2 to exemplify the use of the inference methods explained above. The positive impact of each member's CVS in the VO1's CVS is computed and from the results obtained (see Table 3), we can observe that University A's CVS and Research Center's CVS have a positive impact on VO1's CVS. 
Table 3. Positive Impact results

\begin{tabular}{|c|c|c|}
\hline & $\begin{array}{l}\mathbf{N}^{\mathbf{0}} \text { positive } \\
\text { impacts }\end{array}$ & Positive impacts \\
\hline Factory A & 0 & \\
\hline University A & 1 & $\begin{array}{c}\text { The knowledge value has a high positive impact on } \\
\text { innovation value. }\end{array}$ \\
\hline Research Center & 1 & $\begin{array}{c}\text { The uniqueness value has a fair positive impact on } \\
\text { innovation value. }\end{array}$ \\
\hline
\end{tabular}

The analysis of the potential for conflicts among CNO members (see Table 4) shows that there is a potential for conflict between Factory A and the Research Center due to the fact that Factory A considers Standardization has an important core-value, which has a negative influence in Innovation and Uniqueness, both core-values of the Research Center.

Table 4. Potential for conflict results

\begin{tabular}{|c|c|c|l|c|}
\hline \multicolumn{2}{|c|}{ Pair of Members } & $\begin{array}{c}\text { \# Potential } \\
\text { Conflicts }\end{array}$ & \multicolumn{2}{c|}{ Core-Values Conflicts } \\
\hline Factory A & University A & 0 & & \\
\hline Factory A & $\begin{array}{c}\text { Research } \\
\text { Center }\end{array}$ & 2 & standardization and uniqueness & high \\
\cline { 3 - 5 } & University A & 0 & & standardization and innovation \\
\hline Research Center & Unive & & \\
\hline
\end{tabular}

\section{Core Value System Management Tool}

In the previous section, the process of core-value definition and analysis was briefly described. In order to be able to implement this in a real world context, a tool to support the CVS management and to assist the analysis process was developed. The purpose of the tool is not to fully automate the process of Core Value System analysis, but rather to assist the analysis process during the VO and VBE management.

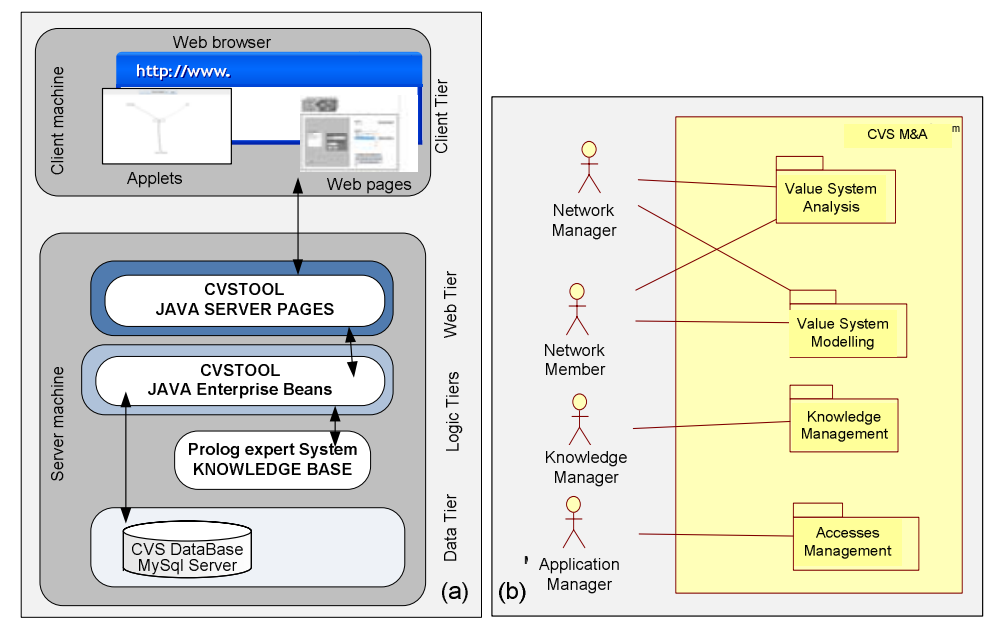

Fig. 5. (a) CVS Tool Technological Architecture (b) - CV Use Case Diagram 
Essentially, the Core Value System analysis can be performed among CNO members' Core Value Systems, or between the CNO's Core Value System and the Core Value System of a partner or a potential partner. In order to be able to support these main features, four components are implemented (see Fig $5 b$ ):

- Core-values knowledge management - To be used by the knowledge experts, in order to specify core-values and their characteristics.

- Core Value System management - To be used by brokers, network managers and network member in order to define their Core Value Systems.

- Core Value System Analysis - To be used by brokers, network managers and network members in order to analyze their Core Value Systems.

- Access management tool - Provides features that allow the application manager to configure accesses to the application according to the user profiles.

As this application was developed to be used in a network context, where users are disperse, a web access to the application is a requirement. For its implementation a client server multitier architecture was adopted, as it is illustrated in Fig. 5a. The application was developed using the J2EE platform. The database was implemented in MySql. In order to implement the graphical features to support the causal maps and the graphs, the JUNG API is used. The implementation of a reference knowledge base is done using SWI-Prolog, and all the reasoning methods are implemented in Prolog and accessed via Java Enterprise Beans.

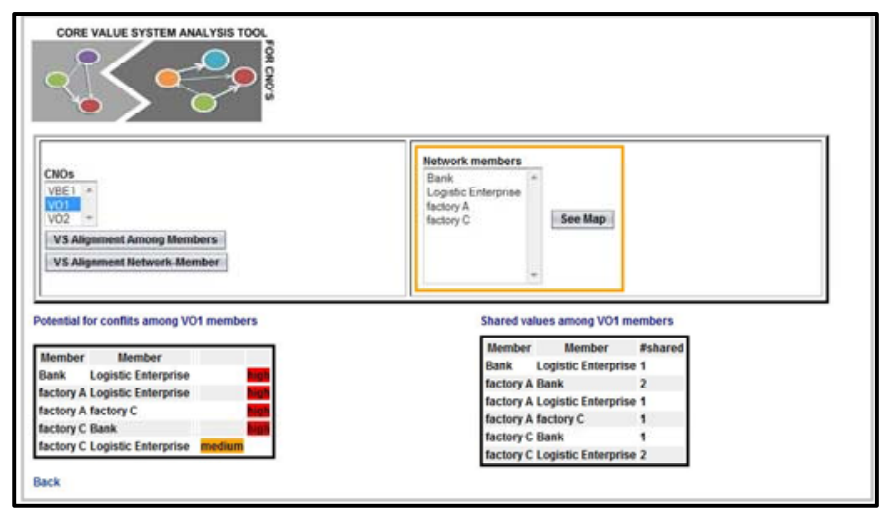

Fig. 6. CVS Analysis tool for CNO's - CVS analysis

Two screen-shots of the application are presented, in order to give a brief view of its features. The results of the qualitative inference for the Core Value System alignment among CNO members are shown in Fig. 6. The map that represents the corevalues held by the network members is shown in Fig. 7. 


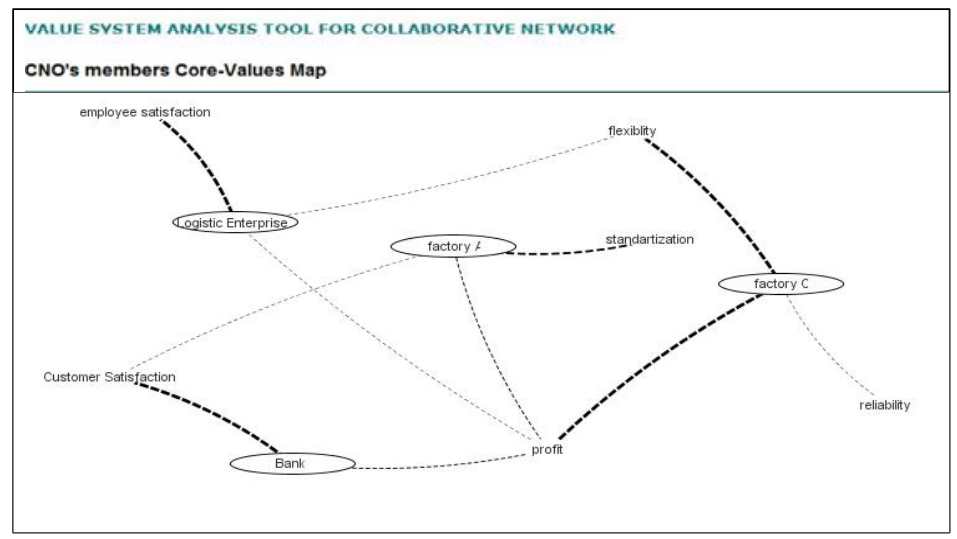

Fig. 7. CVS Analysis tool for CNO's - Analysis Maps

\section{Conclusion}

A qualitative reasoning approach to analyze Core Value Systems in collaborative environments has been proposed. The reasoning methods presented were supported in an analysis framework based on qualitative causal maps and graphs. This approach has the following main advantages: (i) facilitates the representation of knowledge about core-values; (ii) increases the "transparency" and the understandability of the reasoning mechanisms due to the fact that decision tables are expressed in qualitative terms; (iii) makes easier the interpretation of the outputs for all agents of the decision making process, because outputs are expressed totally in qualitative terms. The web application developed to support the core-Value System management and the analysis of Core Value Systems will allow the validation of the proposed inference methods in real world scenarios.

\section{Acknowledgements}

This work was supported in part by the Portuguese "Fundação para a Ciência e a Tecnologia" through a $\mathrm{PhD}$ scholarship.

\section{References}

1. Zineldin, M.A.: Towards an ecological collaborative relationship management A "co-opetive" perspective. European Journal of Marketing 32, 1138-1164 (1998)

2. Macedo, P., Sapateiro, C., Filipe, J.: Distinct Approaches to Value Systems in Collaborative Networks Environments. In: Network-Centric Collaboration and Supporting Frameworks, vol. 224, pp. 111-120. Springer, Boston (2006)

3. Abreu, A., Camarinha Matos, L.M.: On the role of value systems to promote the sustainability of collaborative environments. International Journal of Production Research 46, 1207-1229 (2008) 
4. Afsarmanesh, H., Camarinha-Matos, L.M., Ermilova, E.: Vbe Reference Framework Methods and Tools for Collaborative Networked Organizations, pp. 35-68. Springer, Heidelberg (2008)

5. Camarinha-Matos, L., Macedo, P., Abreu, A.: Analysis of Core-values Alignment in Collaborative Networks. In: Camarinha-Matos, L.M., Picard, W. (eds.) Pervasive Collaborative Networks, pp. 52-64. Springer, Poznan (2008)

6. Abreu, A., Macedo, P., Camarinha-Matos, L.M.: Elements of a methodology to assess the alignment of core-values in collaborative networks. International Journal of Production Research 47, 4907-4934 (2009)

7. Budescu, D.V., Wallsten, T.S.: Consistency in interpretation of probabilistic phrases. Organizational Behavior and Human Decision Processes 36, 391-405 (1985)

8. Olson, D., Moshkovich, H., Schellenberger, R.: Consistency and Accuracy in Decision Aids: Experiments with Four Multiattribute Systems. Decision Sciences 26, 723-747 (1995)

9. Eden, C.: The Analysis of Cause Maps. Journal of Managemnet Studies 29 (1992)

10. Montibeller, G., Belton, V.: Qualitative operators for reasoning maps: Evaluating multicriteria options with networks of reasons. European Journal of Operational Research 195, 829-840 (2009)

11. Hall, B.: Values Shift: A Guide to Personal and Organizational Transformation. Twin Lights Publishers, Rockport (1995)

12. Barrett, R.: Building a Vison-Guided, Values-Driven organization. ButterworthHeinemann (2006)

13. Rekom, J.V., Riel, C.B.M.V., Wierenga, B.: A Methodology for Assessing Organizational Core Values. Journal of Management Studies 43, 175-201 (2006)

14. Camarinha-Matos, L., Macedo, P.: A conceptual model of value systems in collaborative networks. Journal of Intelligent Manufacturing (2008) 